\title{
Asymmetric Local Government Consolidations with Heterogeneous Local Public Goods
}

\author{
Akiyoshi Furukawa \\ School of Economics, Chukyo University, Nagoya, Japan \\ Email: ecockawa@mecl.chukyo-u.ac.jp \\ Received 20 February 2014; revised 20 March 2014; accepted 8 April 2014 \\ Copyright (C) 2014 by author and Scientific Research Publishing Inc. \\ This work is licensed under the Creative Commons Attribution International License (CC BY). \\ http://creativecommons.org/licenses/by/4.0/ \\ c) (i) Open Access
}

\begin{abstract}
This paper analyzes the consolidation of asymmetric local governments. When a small district merges into a larger one, the consolidating government can provide a higher level of public services. Normally, residents in large districts favor consolidation while residents in small district oppose it. This paper shows a condition in which desirable consolidation is realized. The result is that only when fixed costs exist within which the public good is produced after consolidation and the commuting cost is very low, is consolidation realized. In an alternate case, consolidation does not occur although it is desirable.
\end{abstract}

\section{Keywords}

\section{Consolidation, Local Public Goods, Asymmetric District, Commuting Cost}

\section{Introduction}

In the literature, a regional population is analyzed to improve the efficiency of local government. As such a regional population is large, the local government can utilize economies of scale. For example, when a regional population is small, the local government cannot produce some public goods that have high fixed costs (following Blume and Blume [1] and Braid [2], these goods include museums, zoos, libraries and sports facilities). If the regional population is large, the local government can provide public goods because it can accept that cost owing to a decreasing average cost. As a result, the region enjoys a variety of public goods. Hinnerich [3] showed some studies that analyzed the relationship between larger local governments and the economies of scale. Conley and Dix [4], Sasaki [5], Anas and Xiong [6] and Anas and Xiong [7] analyzed the optimal population of a local government. Alesina and Spolaore [8] examined the number and size of nations. The consolida- 
tion of local governments is a measure that accommodates a larger regional population. For example, Orutuño-Ortin and Sempere [9], and Blume and Blume [1] have analyzed fiscal integration.

Local governments decide whether they will integrate into a larger municipality or to remain separate. When each local government believes that it is better off by merging into a larger region, consolidation is realized. However, should one of the local governments oppose consolidation, it will not be realized. For example, Bolton and Roland [10], and Ellingsen [11] have analyzed that consolidation. Such voluntary behaviors of local governments may not be desirable from a social welfare viewpoint. For example, consider consolidations in a city and village. Public services provided by the city bring more benefits than a village does. However, this good is not always provided because of its greater cost. After consolidation, however, residents in the village will share that cost and the good can be produced. But inhabitants of a village are likely to oppose consolidation because they get a much smaller benefit from services provided by the city. For example, commuting cost and the larger tax burden decrease this benefit. Such a consolidation may not be realized though it is socially desirable. This paper analyzes the conditions under which a voluntary merger of local governments is socially desirable.

This paper considers two asymmetric local governments. Dur and Staal [12] utilized two asymmetric districts, i.e., a city and a village. However, both districts differed only in population. From a public service provided by the local government, both districts are symmetric. In general, however, these public goods are asymmetric. For example, Braid [2] analyzed the local public goods that some jurisdictions provide and others do not. This paper considers two districts (the city and the village) that provide heterogeneous public goods. Public services provided by the city bring more benefits than the village does. However, this good is not always provided because of its greater cost. After consolidation, however, residents in the village will share that cost and the good can be produced. Given those conditions, this paper analyzes whether or not local governments will consolidate voluntarily when consolidation is socially desirable.

The remainder of the paper is divided as follows: Section 2 shows this paper's model; Section 3 examines consolidation; Section 4 shows results; and Section 5 concludes the paper.

\section{Model}

The model is based on Dur and Staal [12]. The economy is composed of many regions, and this paper analyzes one region within that economy. Each region consists of two districts. District 1 is a city and district 2 is a village. The population size of district $i$ is $l_{i}(i=1,2)$, and this paper's model assumes $l_{1}>l_{2}$. That is, the population of the city is larger than that of the village. Each resident is homogeneous and immobile. $y$ is the per capita income exogenously defined. Residents utilize that income to purchase a private good and to pay a tax. The model assumes that the income is sufficiently large.

Initially, each district constitutes a municipality which provides local public goods that are financed by a lump sum tax. In district 1 , two kinds of local public goods, $q$ and $g$, are provided. The local public good $q$ is produced under an increasing-returns technology. Production of this good requires a fixed cost. This good has a positive spillover effect. That is, residents in district 2 can utilize the good with a commuting cost. The local public good $g$ is produced under constant-returns and does not have a spillover effect. That is, only residents in the district where the good is produced can utilize it. In district 2, the local public good $g$ is produced under a constant-returns technology similar to the good in district 1 . This good can be utilized by residents in region 2 .

The utility function of residents in district 1 is

$$
U_{1}=\sqrt{g_{1}}+\sqrt{q}+y-t_{1}
$$

where $g_{1}$ and $q$ are local public goods, and $t_{1}$ is a local lump-sum tax. In district 2, the utility function is as follows:

$$
U_{2}=\sqrt{g_{2}}+\sqrt{\frac{q}{\tau}}+y-t_{2}
$$

Residents in district 2 should commute to district 1 when they consume the local public good $q . \tau(\tau>1)$ represents that commuting cost.

Producing one unit of the local public good $g$ requires one unit of the private good. Similarly, the private good required for the production of $q$ is $a+q$, where $a$ represents a fixed input requirement and $q$ is the amount of public good. These goods are financed by a local lump-sum tax. In district 1 , the local government's budget 
constraint is

$$
a+q+g_{1}=t_{1} l_{1}
$$

And in district 2, that constraint is:

$$
g_{2}=t_{2} l_{2}
$$

When the local government acts independently, it maximizes the sum of each resident's utility subject to the budget constraint. Then the following results arise. If $a>\frac{l_{1}^{2}}{4}$, the local government in the city does not produce the local public good $q$ because of the higher fixed cost. Conversely, if $a<\frac{l_{1}^{2}}{4}$, the fixed cost is not high. Then, the local government in the city produces the local public good $q$.

\section{Consolidation and Commuting Cost}

\subsection{Consolidation}

Section 2 shows that the local public good of the city is not always provided because of higher cost. This section analyzes whether or not consolidation can resolve this problem.

When consolidation is realized, two districts form one municipality that provides the local public good $q$ in the city, and local public goods $g_{1}, g_{2}$ are provided in each region. For residents in each region, varieties of public goods do not change. In the village, residents must pay the commuting cost whether consolidation realizes or not, because it does not change the geographical distance. These public goods are financed by the lumpsum tax imposed on all individuals. That tax is uniform across districts.

The consolidated government maximizes the social welfare that is the sum of utilities in the economy.

$$
\max _{g_{1}, g_{2}, q} l_{1}\left(\sqrt{g_{1}}+\sqrt{q}\right)+l_{2}\left(\sqrt{g_{2}}+\sqrt{\frac{q}{\tau}}\right)+\left(l_{1}+l_{2}\right) y-\left(a+q+g_{1}+g_{2}\right)
$$

where $\tau$ represents the commuting cost residents in the village must pay. The consolidation does not change this cost.

From this maximization, the consolidated government behaves as follows. If $a>\frac{1}{4}\left(l_{1}+\frac{l_{2}}{\sqrt{\tau}}\right)^{2}$, the government does not produce the local public good $q$ because of higher fixed cost. Conversely, if $a<\frac{1}{4}\left(l_{1}+\frac{l_{2}}{\sqrt{\tau}}\right)^{2}$, the government produces the good because the fixed cost is not higher for the government and the provision of the good improves the welfare. In this economy, consolidation does not decrease the social welfare. That is, it is socially desirable.

\subsection{The Incentive for Consolidation}

In the economy, consolidation requires the consent of both governments. Each government favors consolidation when the sum of residents' utilities increases. First, we consider the case of the city. Whether the public $\operatorname{good} q$ is produced or not, the individual's utility in the city is better off when consolidation occurs. That is because the village shares the cost of public goods in the case of consolidation. Therefore, the city always favors consolidation.

Next, in the village, the following results arise: when $a>\frac{1}{4}\left(l_{1}+\frac{l_{2}}{\sqrt{\tau}}\right)^{2}$, because of the higher fixed cost, the public good $q$ is not produced whether or not consolidation is realized. Then, consolidation decreases utility in the village. Therefore, the village opposes consolidation. Next, consider the case $a<\frac{l_{1}^{2}}{4}$. Because of the lower 
fixed cost, the public good $q$ is always produced. In this case, consolidation decreases the utility and the village opposes consolidation.

Consider the third case when $\frac{l_{1}^{2}}{4}<a<\frac{1}{4}\left(l_{1}+\frac{l_{2}}{\sqrt{\tau}}\right)^{2}$. In this case, the public good $q$ is produced only when consolidation occurs. Then, the utility does not change whether or not consolidation is realized if

$$
\tau=\tau^{*}=\left[\frac{l_{1}^{2}+\sqrt{l_{1}^{4}+\left(2 l_{1}^{2}-l_{1} l_{2}+4 a\right)\left(2 l_{1} l_{2}+l_{2}^{2}\right)}}{2 l_{1}^{2}-l_{1} l_{2}+4 a}\right]^{2}
$$

When $\tau>\tau^{*}$, consolidation decreases utility in the village. Therefore, the village opposes consolidation. When the commuting cost is higher, individuals in the village must pay a higher cost for the consumption of public goods. As a result, the benefit of the public good consumption in the village is small compared to the cost. On the other hand, when the commuting cost is smaller, individuals in the village can utilize the public good without the higher commuting cost. Consolidation provides a higher benefit from public goods consumption. Sørensen [13] showed that the cost of political transaction impeded consolidations in Norway. In this paper, the commuting cost behaves as if it were that transaction cost.

Does consolidation occur when it is socially desirable? From the above analysis, Proposition 1 is derived.

Proposition 1. When $\frac{l_{1}^{2}}{4}<a<\frac{1}{4}\left(l_{1}+\frac{l_{2}}{\sqrt{\tau}}\right)^{2}$ and $\tau$ is smaller, desirable consolidation arises. In the opposite case, consolidation does not occur because of the village's opposition, though it is desirable.

When $\frac{l_{1}^{2}}{4}<a<\frac{1}{4}\left(l_{1}+\frac{l_{2}}{\sqrt{\tau}}\right)^{2}$, there is a possibility that consolidation will be realized. In this case, through consolidation, the public good $q$ is produced. Residents of the village must approve consolidation if they want to consume the good. However, when the commuting cost is greater, the village opposes consolidation to avoid the larger burden for that consumption. Only when the commuting cost is smaller, will the village approve consolidation and realize it. Consolidation does not change the commuting cost because spatial district between city and village does not change. But the other measure can decrease this cost. For example, when transport technology developed, the commuting cost is decreasing with the commuting time. That is, transport technology development that the government does not affect promotes consolidation.

When $a>\frac{1}{4}\left(l_{1}+\frac{l_{2}}{\sqrt{\tau}}\right)^{2}$, the public good $q$ is not produced whether consolidation is realized or not. The village increases the tax burden and does not obtain the benefit after consolidation. Therefore, the village opposes the consolidation and does not realize it. When $a<\frac{l_{1}^{2}}{4}$, consolidation increases the amount of public good $q$. Inhabitants of the village get a much larger benefit through consumption of the good, but their tax burden is larger than that benefit. Then, inhabitants of the village oppose consolidation because they can consume the public good $q$ even if it does not arise.

\section{Results and Analysis}

When the local government acts independently and $a>\frac{l_{1}^{2}}{4}$, the local government in the city does not produce the local public good $q$ because of the higher fixed cost. But when consolidation occurs and $a<$ $\frac{1}{4}\left(l_{1}+\frac{l_{2}}{\sqrt{\tau}}\right)^{2}$, the consolidated government produces the good because the fixed cost is not higher for the governmentand the provision of the good improves the welfare. To sum up, when $\frac{l_{1}^{2}}{4}<a<\frac{1}{4}\left(l_{1}+\frac{l_{2}}{\sqrt{\tau}}\right)^{2}$, con- 
solidation increases the social welfare compared to the case in which two districts are independent because the public good $q$ is produced only when consolidation occurs. But, in this case consolidation may not be realized because the local government in the village opposes consolidation.

In the equilibrium, consolidation is realized when each local government believes that it is better off by merging into a larger region. The local government in the city always favors consolidation. Therefore, should the local government in the village approve consolidation, it will be realized. Proposition 1 shows that when $\frac{l_{1}^{2}}{4}<a<\frac{1}{4}\left(l_{1}+\frac{l_{2}}{\sqrt{\tau}}\right)^{2}$ and $\tau<\tau^{*}$, the local government in the village approves consolidation because individuals in the village can utilize the public good without the higher commuting cost through it. Consolidation provides a higher benefit from public goods consumption. Only when a fixed cost exists within that range and the commuting cost is very low, is consolidation realized.

In the other case, consolidation does not occur though it is desirable because the local government in the village opposes consolidation. When $\frac{l_{1}^{2}}{4}<a<\frac{1}{4}\left(l_{1}+\frac{l_{2}}{\sqrt{\tau}}\right)^{2}$ and $\tau>\tau^{*}$, the public good $q$ is produced through consolidation and it increases the social welfare. However, because the commuting cost is greater, the village opposes consolidation to avoid the larger burden for that consumption. When $a>\frac{1}{4}\left(l_{1}+\frac{l_{2}}{\sqrt{\tau}}\right)^{2}$, because of the higher fixed cost, the public good $q$ is not produced whether or not consolidation is realized. In this case, consolidation does not decrease the social welfare. In the village, consolidation decreases utility because it increases the tax burden without the benefit. Therefore, the village opposes the consolidation and does not realize it. When $a<\frac{l_{1}^{2}}{4}$, consolidation increases the amount of public good $q$. In this case, consolidation increases the welfare and inhabitants of the village get a much larger benefit through consumption of the good. But the village opposes the consolidation because their tax burden is larger than that benefit. In this paper, consolidation is socially desirable. But in many cases, it does not realize because of the village's opposition.

\section{Conclusions}

This paper has examined consolidation in local governments. When a small district merges into a larger one, the consolidating government can provide a higher level of public services. Normally, residents in large districts favor consolidation because small districts share the cost of public services, while the large district's loss in consolidation is low. However, residents in a small district oppose consolidation when it results in a large loss from taxes and commuting costs. This paper has shown a condition in which consolidation, though desirable, is realized.

There exists a range of fixed costs within which the public good is produced after consolidation. In this case, consolidation depends on the commuting cost that local governments do not affect. When the commuting cost is very low, the small district gets a larger benefit from public good consumption compared to the tax burden. Then, consolidation is realized. But when the commuting cost is very high, that benefit is comparatively smaller and consolidation is not realized. Only when a fixed cost exists within that range and the commuting cost is very low, is consolidation realized. In the other case, consolidation does not occur though it is desirable. In that case, the national government should encourage consolidation via a redistribution policy. This issue is for further research.

\section{Acknowledgements}

I thank the anonymous referee, Takeshi Miyazaki, Takero Doi, Mototsugu Fukushige, Hiroyuki Hashimoto and Masaya Yasuoka for their helpful comments.

\section{References}

[1] Blume, L. and Blume, T. (2007) The Economic Effects of Local Authority Mergers: Empirical Evidence for German City Regions. Annals of Regional Science, 41, 689-713. http://dx.doi.org/10.1007/s00168-007-0118-6 
[2] Braid, R.M. (2010) Provision of a Pure Local Public Good in a Spatial Model with Many Jurisdictions. Journal of Public Economics, 94, 890-897. http://dx.doi.org/10.1016/j.jpubeco.2010.07.008

[3] Hinnerich, B.T. (2009) Do Merging Local Governments Free Ride on Their Counterparts When Facing Boundary Reform? Journal of Public Economics, 93, 721-728. http://dx.doi.org/10.1016/j.jpubeco.2009.01.003

[4] Conley, J. and Dix, M. (1999) Optimal and Equilibrium Membership in Clubs in the Presence of Spillovers. Journal of Urban Economics, 46, 215-229. http://dx.doi.org/10.1006/juec.1998.2119

[5] Sasaki, K. (2000) Local Public Goods and Their Capital-Gain Effects. Regional Science and Urban Economics, 30, 45-57. http://dx.doi.org/10.1016/S0166-0462(99)00031-9

[6] Anas, A. and Xiong, K. (2003) Intercity Trade and the Industrial Diversification of Cities. Journal of Urban Economics, 54, 258-276. http://dx.doi.org/10.1016/S0094-1190(03)00073-1

[7] Anas, A. and Xiong, K. (2005) The Formation and Growth of Specialized Cities: Efficiency without Developers or Malthusian Traps. Regional Science and Urban Economics, 35, 445-470. http://dx.doi.org/10.1016/j.regsciurbeco.2003.11.001

[8] Alesina, A. and Spolaore, E. (1997) On the Number and Size of Nations. Quarterly Journal of Economics, 112, 10271056. http://dx.doi.org/10.1162/003355300555411

[9] Orutuño-Ortin, I. and Sempere, J. (2006) A Theoretical Model of Nations, Regions and Fiscal Integration. Regional Science and Urban Economics, 36, 132-157. http://dx.doi.org/10.1016/j.regsciurbeco.2005.07.001

[10] Bolton, P. and Roland, G. (1996) Distribution Conflicts, Factor Mobility and Political Integration. American Economic Review, 86, 99-104.

[11] Ellingsen, T. (1998) Externalities vs Internalities: A Model of Political Integration. Journal of Public Economics, 68, 251-268. http://dx.doi.org/10.1016/S0047-2727(97)00090-X

[12] Dur, R. and Staal, K. (2008) Local Public Good Provision, Municipal Consolidation, and National Transfers. Regional Science and Urban Economics, 38, 160-173. http://dx.doi.org/10.1016/j.regsciurbeco.2008.01.005

[13] Sørensen, R.J. (2006) Local Government Consolidations: The Impact of Political Transaction Costs. Public Choice, 127, 75-95. http://dx.doi.org/10.1007/s11127-006-7106-8 